\title{
REAÇÕES DO ALGODOEIRO CNPA-ITA 90 AO CLORETO DE MEPIQUAT ${ }^{1}$
}

\author{
FERNANDO MENDES LAMAS ${ }^{2}$, MANOEL LUIZ FERREIRA ATHAYDE ${ }^{3}$ e DAVID ARIOVALDO BANZATTO 4
}

\begin{abstract}
RESUMO - Com o objetivo de avaliar os efeitos de diferentes doses de cloreto de mepiquat aplicadas parceladamente no algodoeiro (Gossypium hirsutum L.) cv. CNPA-ITA 90, dois experimentos foram conduzidos durante os anos agrícolas de 1993/94 e 1994/95, na Fazenda Itamarati, Ponta Porã, MS. As doses estudadas foram: 1) 0,0 ; 2) $12,5+12,5+25,0(50,0)$; 3) $25,0+25,0+25,0(75,0)$; 4) $0,0+50,0+50,0(100,0)$ e 5) $12,5+62,5+50,0(125,0) \mathrm{g} \mathrm{ha}^{-1}$ de cloreto de mepiquat. O delineamento experimental utilizado foi o de blocos casualizados, com quatro repetições. As aplicações foram efetuadas aos 34, 47 e 62 dias após a emergência (DAE), em 1993/94, e aos 42, 60 e 73 DAE no ano de 1994/95, quando as plantas apresentavam altura média de 51,84 e $93 \mathrm{~cm}$ e 61,79 e $97 \mathrm{~cm}$, respectivamente. Com o aumento da dose de cloreto de mepiquat, verificou-se redução da altura de plantas, da matéria seca foliar, do caule e do total da parte vegetativa, do número de nós, de ramos, do comprimento de ramos, do número de frutos danificados e do número de maçãs, e aumento do número de capulhos totalmente abertos.
\end{abstract}

Termos para indexação: Gossypium hirsutum, algodão, regulador de crescimento, biorregulador.

\section{REACTIONS OF COTTON CNPA-ITA 90 TO MEPIQUAT CHLORIDE}

\begin{abstract}
The effects of different doses of mepiquat chloride on cotton (Gossypium hirsutum L.) plants, cultivar CNPA-ITA 90, during the 1993/94 and 1994/95 growing seasons were evaluated at Itamarati farm, Ponta Porã, MS, Brazil. The doses were split in three application dates and the experimental design was in randomized blocks, with five treatments replicated four times. The treatments were as follows: 1) unsprayed control; 2) $12.5+12.5+25.0$ (50.0); 3) 25.0+25.0+25.0 (75.0); 4) $0.0+50.0+50.0(100.0)$; and 5) $12.5+62.5+50.0(125.0) \mathrm{g} \mathrm{ha}^{-1}$ of mepiquat chloride. The spraying was done at 34, 47 and 62 days after emergence (DAE) in 1993/94 and at 42, 60 and 73 DAE in 1994/95, when the plants were at the average hight of 51, 84 and $93 \mathrm{~cm}$ and 61,79 and $97 \mathrm{~cm}$, respectively. Increasing dose of mepiquat chloride caused decreasing in plant height; leaf stems and total above ground dry matter; number of nodes and branching; the branches length; the number of damaged fruits; the total number of bolls and the number of fully opened bolls.
\end{abstract}

Index terms: Gossypium hirsutum, plant growth regulator, bioregulator.

\section{INTRODUÇÃO}

Na busca da melhoria dos atuais níveis de produtividade e redução dos custos de produção da cultu-

\footnotetext{
${ }^{1}$ Aceito para publicação em 12 de maio de 1999.

Extraído da tese de Doutorado do primeiro autor, apresentada à Faculdade de Ciências Agrárias e Veterinárias da UNESP Campus de Jaboticabal.

${ }^{2}$ Eng. Agrôn., Dr., Embrapa-Centro de Pesquisa Agropecuária do Oeste (CPAO), Caixa Postal 661, CEP 79804-970 Dourados, MS. E-mail: lamas@cpao.embrapa.br

${ }^{3}$ Eng. Agrôn., Dr., Prof. Titular, Dep. de Fitotecnia, FCAV-UNESP, Rod. Carlos Tonani km 5, CEP 14870-000 Jaboticabal, SP.

${ }^{4}$ Eng. Agrôn., Dr., Prof. Adjunto, Dep. de Ciências Exatas, UNESP, Jaboticabal, SP.
}

ra do algodoeiro no Brasil, novas tecnologias vêm sendo incorporadas ao sistema de produção dessa malvácea.

Entre as novas tecnologias em estudo, a manipulação da arquitetura das plantas do algodoeiro com biorreguladores é uma das estratégias agronômicas para o incremento da produtividade (Hodges et al., 1991). O uso desses produtos na cultura do algodoeiro, principalmente quando cultivado em solos de alta fertilidade, vem aumentando, especialmente em propriedades onde se utiliza a colheita mecanizada (Carvalho et al., 1994). A prática de mecanização da colheita é um dos fatores que poderá contribuir para a redução dos custos de produção; por isso tende a aumentar, principalmente em áreas médias e grandes (Carvalho \& Furlani Júnior, 1996). 
Com a utilização de cloreto de mepiquat (cloreto 1,1 - dimethyl piperidinum), é possível o estabelecimento de culturas mais lucrativas, uma vez que seus benefícios potenciais são: redução do crescimento vegetativo, da altura das plantas, do número de nós da haste principal, do tamanho dos internódios, do comprimento dos ramos laterais, aumento do peso de capulho e de 100 sementes, abertura precoce dos frutos, melhor eficiência da colheita e produto de melhor qualidade (Cruz et al., 1982; Barbosa \& Castro, 1983; Reddy et al., 1990; Hodges et al., 1991; Reddy et al., 1992; Carvalho et al., 1994; Beltrão, 1996).

Quando cultivado em condições em que não há limitações de umidade e a disponibilidade de nutrientes é adequada, o algodoeiro produz excessiva vegetação, que interfere negativamente na produção final. Nessa situação, o uso de regulador de crescimento torna-se inevitável (Reddy et al., 1992). O ideal é que a relação entre a matéria seca da parte reprodutiva e a vegetativa do algodoeiro seja maior que uma unidade, pois, nesse caso, a correlação com a produção é positiva (Meredith Junior \& Wells, 1989).

Diversos fatores interferem nos resultados proporcionados pelo uso de cloreto de mepiquat na cultura do algodoeiro, ressaltando-se: população de plantas, cultivar, época de aplicação, forma de aplicação, dose utilizada, fertilidade do solo, umidade e temperatura (York, 1983; Cia et al.,1984; Reddy et al., 1990; Hodges et al.,1991; Wallace et al., 1993; Carvalho et al., 1994; Heitholt et al., 1996).

Beltrão (1996) menciona que a aplicação de regulador de crescimento pode ser feita em uma única vez ou parcelada, dependendo do produto, das condições ambientais e da própria planta, envolvendo o tamanho e o estádio de desenvolvimento.

Aplicações parceladas de cloreto de mepiquat proporcionaram maior redução na altura das plantas, do número de nós, do comprimento dos internódios e maior retenção de frutos, em comparação com a aplicação única (Wallace et al., 1993).

Em Mato Grosso do Sul, o sistema de produção utilizado para a cultura do algodoeiro, vem sofrendo profundas transformações, deixando de ser uma cultura feita em pequenas áreas, para ser uma cultura de grandes áreas, totalmente mecanizada e com a introdução de cultivares modernas, sobre as quais pouco se conhece, principalmente com relação a arquitetura e padrão de crescimento.

Objetivou-se com este trabalho avaliar os efeitos de diferentes doses de cloreto de mepiquat, aplicadas de forma parcelada, sobre algumas características do algodoeiro CNPA-ITA 90.

\section{MATERIAL E MÉTODOS}

Os experimentos foram conduzidos na Fazenda Itamarati, localizada em Ponta Porã, MS, onde a altitude média é de $630 \mathrm{~m}$, com as coordenadas geográficas $22^{\circ} 30^{\prime}$ de latitude $\mathrm{S}$ e $54^{\circ} 44^{\prime}$ de longitude $\mathrm{W}$, durante os anos agrícolas de 1993/94 e 1994/95.

Os experimentos foram conduzidos em um Latossolo Vermelho-Escuro eutrófico, de topografia suavemente ondulada, anteriormente cultivado com soja e trigo durante aproximadamente 12 anos.

Por ocasião da semeadura, foi realizada a seguinte adubação: 23,5 kg ha-1 de $\mathrm{N} ; 164,7 \mathrm{~kg} \mathrm{ha}^{-1}$ de $\mathrm{P}_{2} \mathrm{O}_{5}$; 90,0 kg ha ${ }^{-1}$ de $\mathrm{K}_{2} \mathrm{O} ; 10 \mathrm{~kg} \mathrm{ha}^{-1}$ de $\mathrm{S} ; 15 \mathrm{~kg} \mathrm{ha}^{-1}$ de $\mathrm{Zn}$; $10,7 \mathrm{~kg} \mathrm{ha}^{-1}$ de $\mathrm{Cu}$; e $1,2 \mathrm{~kg} \mathrm{ha}^{-1}$ de B. A adubação de cobertura com $\mathrm{N}$ totalizou $149,0 \mathrm{~kg} \mathrm{ha}^{-1}$, que foi aplicado parcelado, via pivô central, utilizando-se como fonte de $\mathrm{N}$ a uréia.

A semeadura foi realizada no espaçamento de $0,76 \mathrm{~m}$ entre fileiras. No primeiro ano, a emergência foi em $5 / 11$ e no segundo em $9 / 11$, com densidade de dez plantas. A cultivar de Gossypium hirsutum L. raça latifolium Hutch. utilizada foi a CNPA-ITA 90. Durante o período de condução dos experimentos, a precipitação pluvial na área experimental variou entre 120 e $190 \mathrm{~mm}$ mensal, sendo as maiores precipitações ocorridas durante o mês de janeiro e as menores no mês de março; a temperatura média variou entre $20^{\circ} \mathrm{C}$ e $28^{\circ} \mathrm{C}$.

As doses de cloreto de mepiquat estudadas, bem como o esquema de parcelamento adotado, encontram-se na Tabela 1.

As aplicações de cloreto de mepiquat foram realizadas no ano agrícola de 1993/94 nas seguintes épocas: primeira aplicação - 34 dias após a emergência (DAE) - plantas com $51 \mathrm{~cm}$; segunda aplicação - 47 DAE - plantas com $84 \mathrm{~cm}$; e terceira aplicação - 62 DAE - plantas com $93 \mathrm{~cm}$; e no ano agrícola de 1994/95 nas seguintes épocas: primeira aplicação - $42 \mathrm{DAE}$ - plantas com $61 \mathrm{~cm}$; segunda aplicação - 60 DAE - plantas com $79 \mathrm{~cm}$; e terceira aplicação - 73 DAE - plantas com $97 \mathrm{~cm}$.

Em ambos os anos, as aplicações do produto foram realizadas nas primeiras horas da manhã, com avião agrí- 
cola, acoplado com barra de pulverização, utilizando-se bicos do tipo D8, pressão de $25 \mathrm{lb} \mathrm{kgf}^{-1}$ e vazão de $30 \mathrm{~L} \mathrm{de}$ calda por hectare.

Dentro de cada parcela experimental foram amostradas 27 plantas, em intervalos de sete dias, para determinação da altura, e a cada catorze dias, durante o período compreendido entre o início da aplicação dos tratamentos até aos 105 e 106 DAE, nos anos de 1993/94 e 1994/95, respectivamente, para as seguintes determinações: número de nós do eixo principal; comprimento de ramos do quinto, sétimo, nono e décimo primeiro nó; número de botões florais e de frutos. Após essas determinações, das 27 plantas efetuou-se a separação de folhas, ramos, botões florais, flores e frutos para a determinação de matéria seca de cada uma das partes das plantas.

As partes separadas foram acondicionadas em sacos de papel e levadas à estufa de circulação forçada a $65^{\circ} \mathrm{C}$, até a obtenção de peso constante, quando então foi feita a pesagem da matéria seca.

Quando aproximadamente $70 \%$ dos frutos estavam completamente abertos, em 27 plantas, foram feitas as seguintes avaliações: número de capulhos totalmente e parcialmente abertos; número de frutos total e parcialmente danificados; número de maçãs e altura de plantas.

O delineamento experimental utilizado foi o de blocos casualizados, com quatro repetições. As parcelas experimentais foram de 45,6 x 600,0 m. Todas as avaliações foram feitas em plantas localizadas na parte central de cada parcela experimental.

Os resultados obtidos, a partir das avaliações realizadas 14 dias após a última aplicação do cloreto de mepiquat, foram submetidos à análise de variância e posteriormente à análise de regressão polinomial, ajustando-se para cada variável, quando o efeito do tratamento foi significativo $(\mathrm{P}<0,05)$ pelo teste $\mathrm{F}$, uma equação de regressão.

TABELA 1. Tratamentos estudados e esquema de parcelamento das doses de cloreto de mepiquat. Ponta Porã, MS, 1996.

\begin{tabular}{|c|c|c|c|c|}
\hline \multirow[t]{2}{*}{ Tratamentos } & \multicolumn{4}{|c|}{ Aplicações parceladas (g ha ${ }^{-1}$ de i.a.) } \\
\hline & $1^{\mathrm{a}}$ & $2^{-\mathrm{a}}$ & $3^{-\mathrm{a}}$ & Total \\
\hline 1 & 0,0 & 0,0 & 0,0 & 0,0 \\
\hline 2 & 12,5 & 12,5 & 25,0 & 50,0 \\
\hline 3 & 25,0 & 25,0 & 25,0 & 75,0 \\
\hline 4 & 0,0 & 50,0 & 50,0 & 100,0 \\
\hline 5 & 12,5 & 62,5 & 50,0 & 150,0 \\
\hline
\end{tabular}

\section{RESULTADOS E DISCUSSÃO}

No ano agrícola de 1993/94, as menores alturas de planta $(\mathrm{cm})$ foram estimadas para as doses de $112,91,102,12,92,48$ e $105,00 \mathrm{~g} \mathrm{ha}^{-1}$ de cloreto de mepiquat, aos 77, 91 e 105 DAE; em 1994/95, para as doses de 86,2 e 78,3 $\mathrm{g} \mathrm{ha}^{-1}$ de cloreto de mepiquat, aos 86 e 106 DAE (Fig. 1).

Pela Fig. 2, verifica-se que no ano agrícola de 1993/94 a altura final decresceu de forma quadrática com o aumento da dose de cloreto de mepiquat. $\mathrm{O}$ ideal é que as plantas, na colheita, tenham altura entre 1,20-1,30 m, o que, no presente trabalho, foi obtido com dose entre $0,0-25,0 \mathrm{~g} \mathrm{ha}^{-1}$ de cloreto de mepiquat. No ano agrícola de 1994/95, esta altura foi obtida na ausência do cloreto de mepiquat (Fig. 2). Em ambos os anos, os resultados obtidos não deixam qualquer dúvida de que o cloreto de mepiquat reduz o crescimento das plantas, o que foi verificado em todos os períodos avaliados. Os resultados obtidos no presente trabalho corroboram os obtidos por Barbosa \& Castro (1983), Cia et al. (1984), Stuart et al. (1984), Laca-Buendia (1989), Reddy et al. (1992), Wallace et al. (1993) e Carvalho et al. (1994); e são diferentes dos obtidos por Cruz et al. (1982), que concluíram não haver diferenças significativas entre quatro doses de cloreto de mepiquat sobre a altura de plantas.

A produção de matéria seca foliar foi significativamente afetada pelas doses de cloreto de mepiquat, nos dois anos de condução do trabalho. No primeiro ano, os valores obtidos aos 91 e 105 DAE se ajustaram a uma equação de regressão cúbica e linear, respectivamente (Fig. 3). No segundo ano, na avaliação realizada aos $86 \mathrm{DAE}$, a produção de matéria seca foliar decresceu linearmente com o aumento da dose de cloreto de mepiquat (Fig. 3). Embora as plantas tenham atingido menor altura no ano agrícola de 1994/95, a matéria seca foliar foi maior do que a estimada para o ano agrícola de 1993/94. Os resultados obtidos no presente trabalho são semelhantes aos de Barbosa \& Castro (1983), Stuart et al. (1984) e Fernandez et al. (1991), que relatam sobre o efeito do regulador de crescimento na redução da área foliar.

Nos dois anos de condução do trabalho, a matéria seca do caule foi significativamente influencia- 
da pelas doses de cloreto de mepiquat. No primeiro ano, na avaliação realizada aos 77 DAE o efeito foi linear, e aos 91 e 105 DAE o efeito foi quadrático (Fig. 4); no segundo ano, nos dois períodos avalia-

\section{(A)}

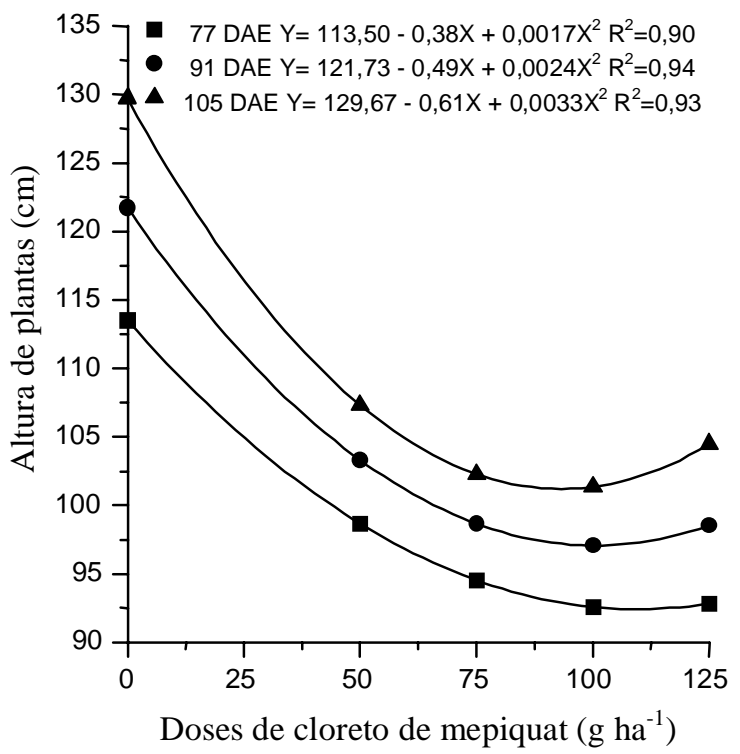

(B)

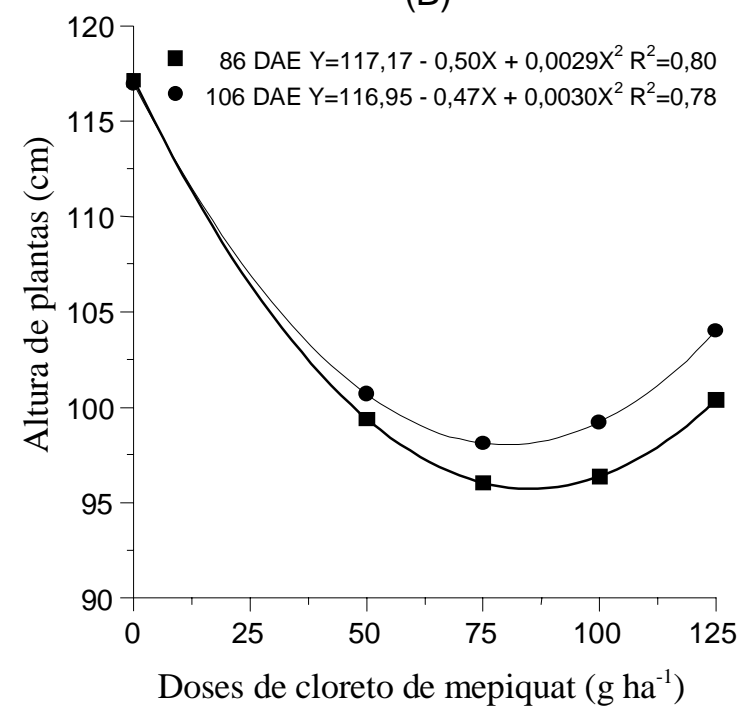

FIG. 1. Efeito de doses cloreto de mepiquat na altura de plantas, aos 77, 91 e 105 DAE, em 1993/94 (A) e aos 86 e 106 DAE, em 1994/95 (B). Ponta Porã, MS, 1994/95. dos, o ajuste foi linear. Este efeito pode ser explicado como sendo devido ao menor crescimento do caule em função dos tratamentos aplicados. De acordo com Reddy et al. (1990), com a aplicação de cloreto de mepiquat têm-se plantas mais compactas, e isto se deve ao menor crescimento do caule e dos ramos provocado pelo produto, o que, segundo Meredith
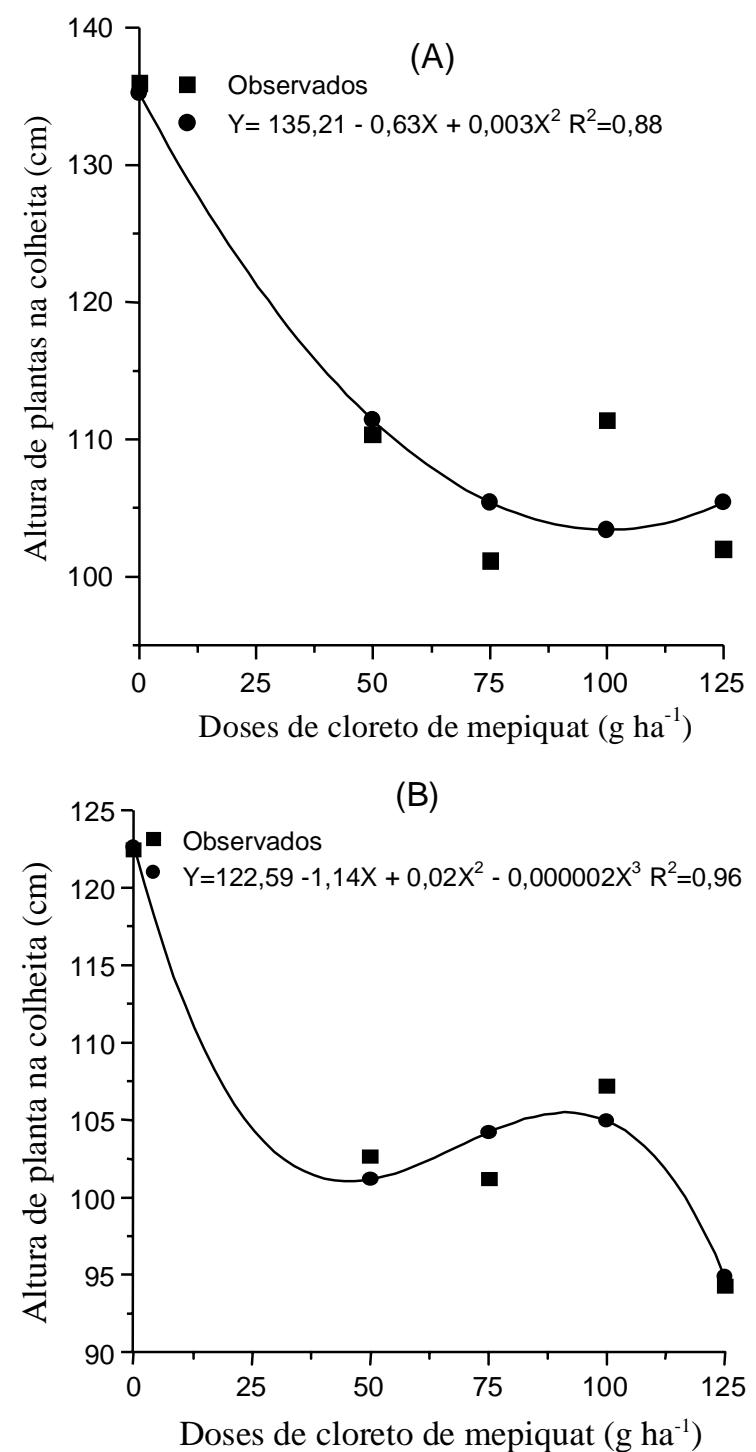

FIG. 2. Efeito das doses de cloreto de mepiquat na altura de plantas, aos 129 DAE, em 1993/94 (A) e aos 134 DAE, em 1994/95 (B). Ponta Porã, MS, 1994/95. 
(A)

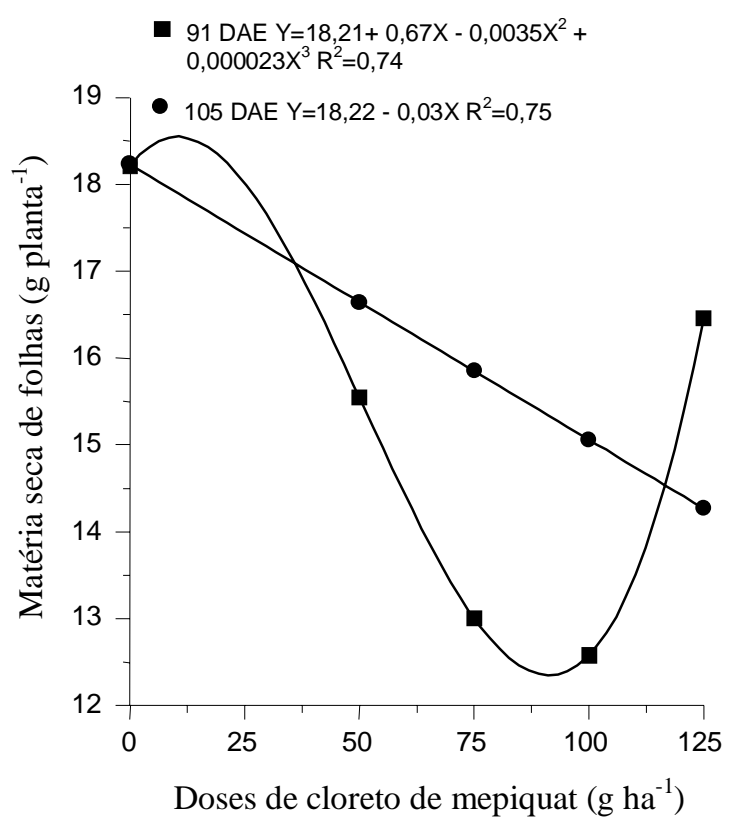

(B)

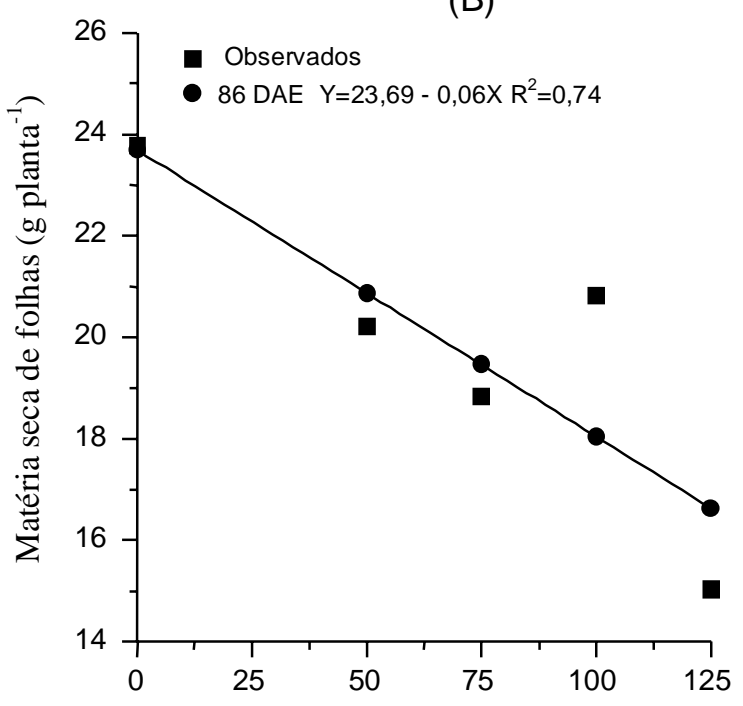

Doses de cloreto de mepiquat $\left(\mathrm{g} \mathrm{ha}^{-1}\right)$

FIG. 3. Efeito das doses de cloreto de mepiquat na matéria seca foliar, aos 91 e $105 \mathrm{DAE}$, em 1993/94 (A) e aos 86 DAE, 1994/95 (B). Ponta Porã, MS, 1994/95.
Junior \& Wells (1989), é vantajoso, pois assim têmse plantas em que a relação entre a matéria seca da parte reprodutiva e vegetativa é maior que uma unidade, e tal relação se correlaciona positivamente com a produção de algodão.

Quando se comparam os efeitos do cloreto de mepiquat sobre a matéria seca foliar (Fig. 3) e do

(A)

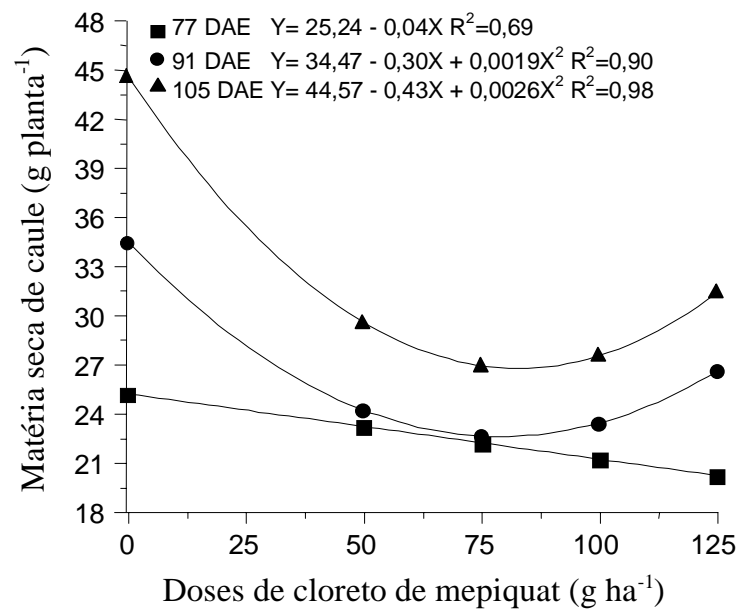

(B)

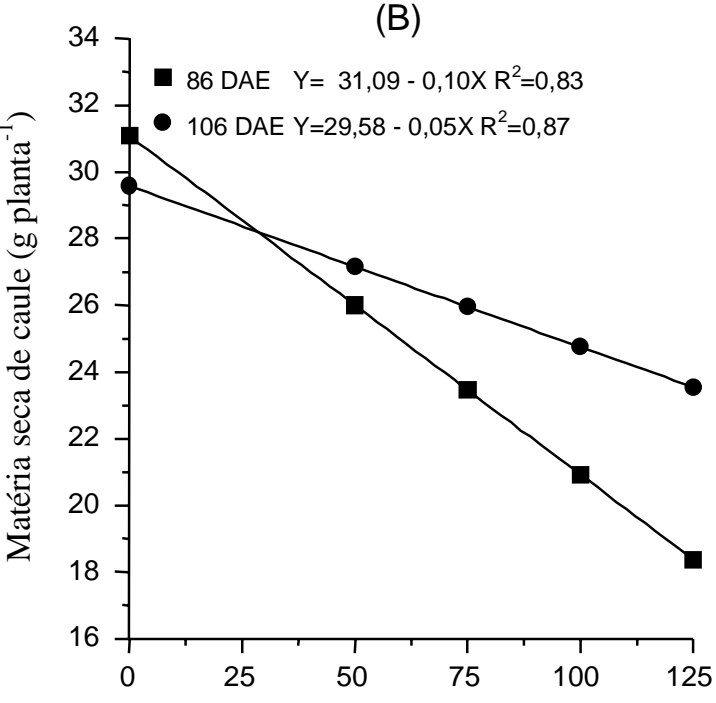

Doses de cloreto de mepiquat $\left(\mathrm{g} \mathrm{ha}^{-1}\right)$

FIG. 4. Efeito das doses de cloreto de mepiquat na matéria seca do caule, aos 77, 91 e $105 \mathrm{DAE}$ em 1993/94 (A), e aos 86 e 106 DAE, em 1994/95 (B). Ponta Porã, MS, 1994/95.

Pesq. agropec. bras., Brasília, v.35, n.3, p.507-516, mar. 2000 
caule (Fig. 4), é possível verificar que o produto tem atuação semelhante sobre as diferentes partes da planta, provocando redução da matéria seca.

$\mathrm{O}$ efeito do cloreto de mepiquat sobre a matéria seca total da parte vegetativa foi significativo, com os dados se ajustando a equações de natureza linear e quadrática, dependendo do período avaliado (Fig. 5). Com um menor crescimento da parte vegetativa, têm-se plantas mais equilibradas, cuja relação entre matéria seca da parte reprodutiva e vegetativa tende a atingir valores próximos a um. Resultados semelhantes foram obtidos por Barbosa \& Castro (1983) e por Reddy et al. (1990).

O número de ramos por planta, nos dois anos estudados, decresceu linearmente com o aumento da dose de cloreto de mepiquat (Fig. 6). Para a produção de algodão em caroço, os ramos frutíferos (simpodiais) são os mais importantes; assim, se houver redução destes, a produção poderá ser afetada negativamente. No presente trabalho, a avaliação foi feita indistintamente, não separando ramos frutíferos de vegetativos.

Barbosa \& Castro (1983), Meredith Junior \& Wells (1989), Fernandez et al. (1991) e Cothren \& Oosterhuis (1993) relatam que o cloreto de mepiquat altera a partição da biomassa, inibindo o crescimento de determinadas partes e estimulando outras, e que a combinação desses efeitos confere maior eficiência às plantas, inclusive maior tolerância ao estresse hídrico.

Com o aumento da dose de cloreto de mepiquat nos dois anos de estudos, o número de nós por planta decresceu linearmente (Fig. 7), comportamento que é semelhante ao verificado para número de ramos. Para Mauney (1986), o número de nós do eixo principal é de grande importância para a produtividade do algodoeiro, pois os ramos frutíferos são formados a partir dos nós do eixo principal. Entretanto, de acordo com resultados obtidos por Medeiros \& Vieira, citados por Beltrão \& Azevedo (1993), mais de $80 \%$ da produção de algodão em caroço é oriunda de ramos frutíferos, localizados entre o quinto e décimo primeiro nós. Isto permite concluir que, a partir do décimo primeiro nó, a participação na produção total é de pequena importância, e que as estruturas reprodutivas formadas, a partir dessa posição, serão quase que somente drenos de fotoassi- milados, com contribuição muito pequena para a produção final. Os resultados obtidos no presente trabalho são semelhantes aos de Reddy et al. (1990, 1992) e Wallace et al. (1993).

O comprimento de ramos do quinto, sétimo, nono e décimo primeiro nós avaliados aos 105 DAE foi

\section{(A)}

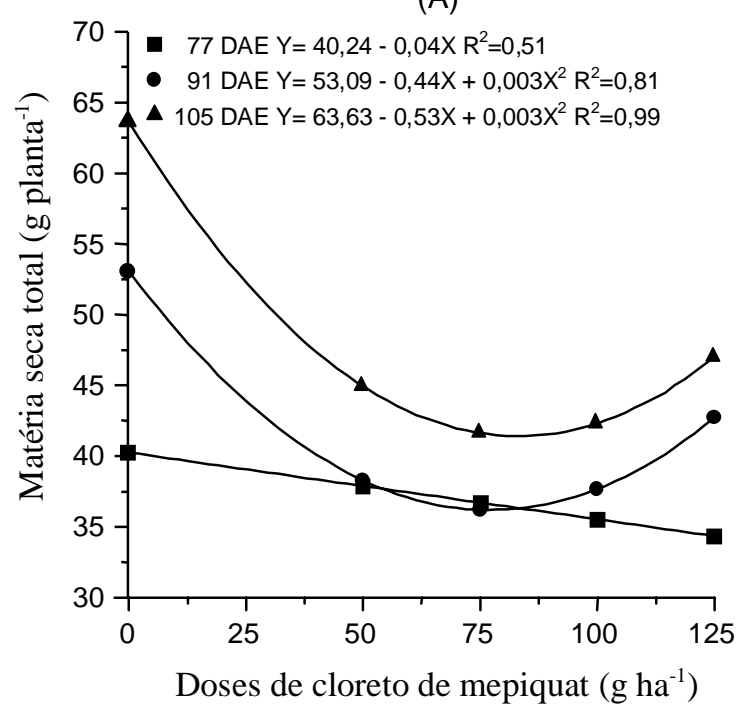

(B)

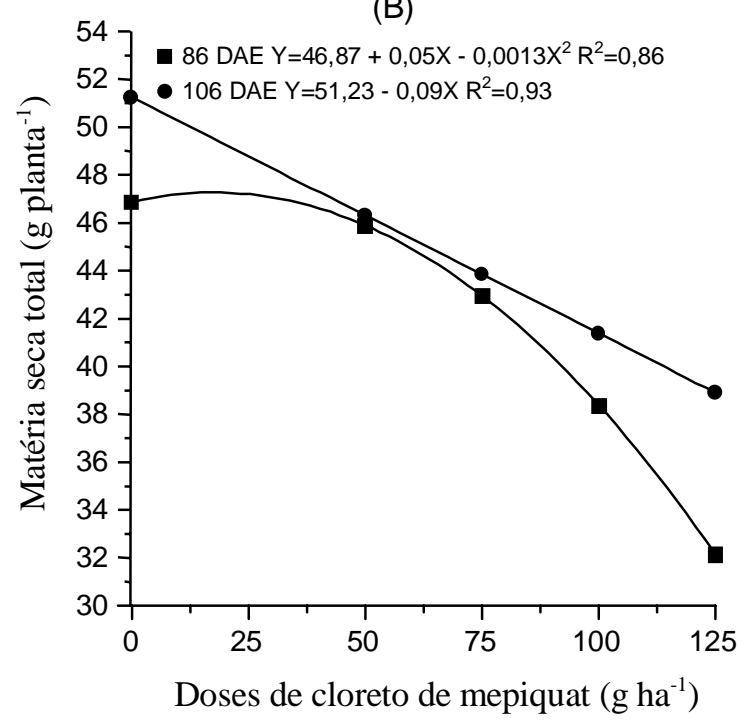

FIG. 5. Efeito das doses de cloreto de mepiquat na matéria seca total da parte vegetativa, aos 77 , 91 e 105 DAE, em 1993/94 (A), e aos 86 e 106 DAE em 1994/95 (B). Ponta Porã, MS, 1994/95. 
influenciado significativamente pelas doses de cloreto de mepiquat, com os dados se ajustando à curvas de regressão linear e quadrática (Fig. 8). De acordo com Reddy et al. (1990), o cloreto de

(A)

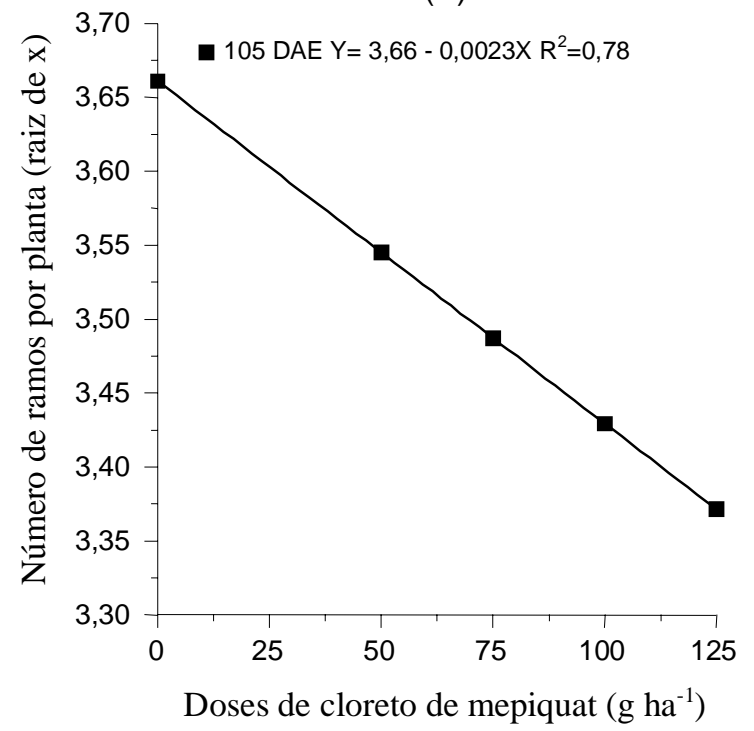

(B)

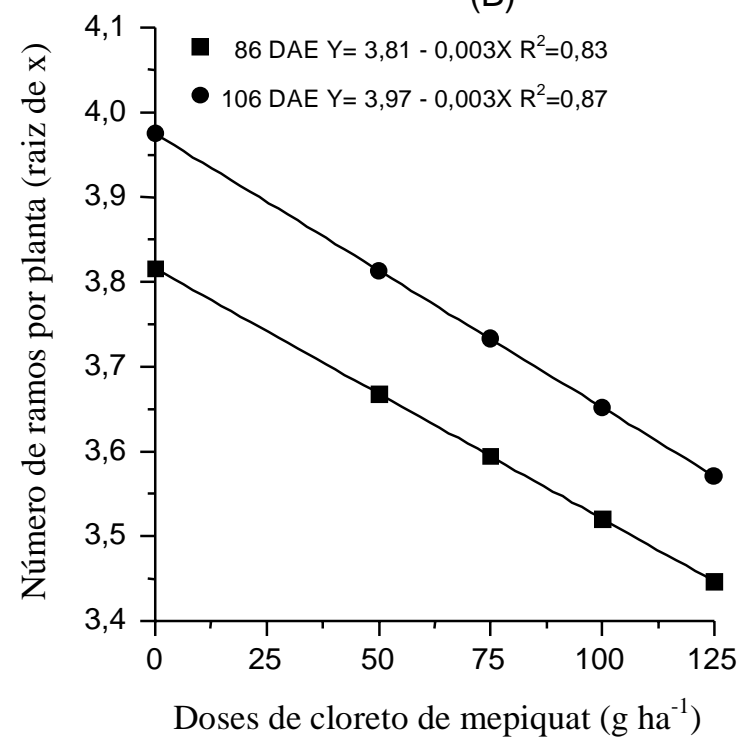

FIG. 6. Efeito das doses de cloreto de mepiquat no número de ramos por planta, aos 105 DAE em 1993/94 (A), e aos 86 e 106 DAE, em 1994/95 (B). Ponta Porã, MS, 1994/95. mepiquat altera o balanço entre ramos vegetativos e frutíferos, favorecendo o segundo. Cruz et al. (1982) e Fernandez et al. (1991) também relatam que o produto em estudo inibe o crescimento de ramos.

(A)
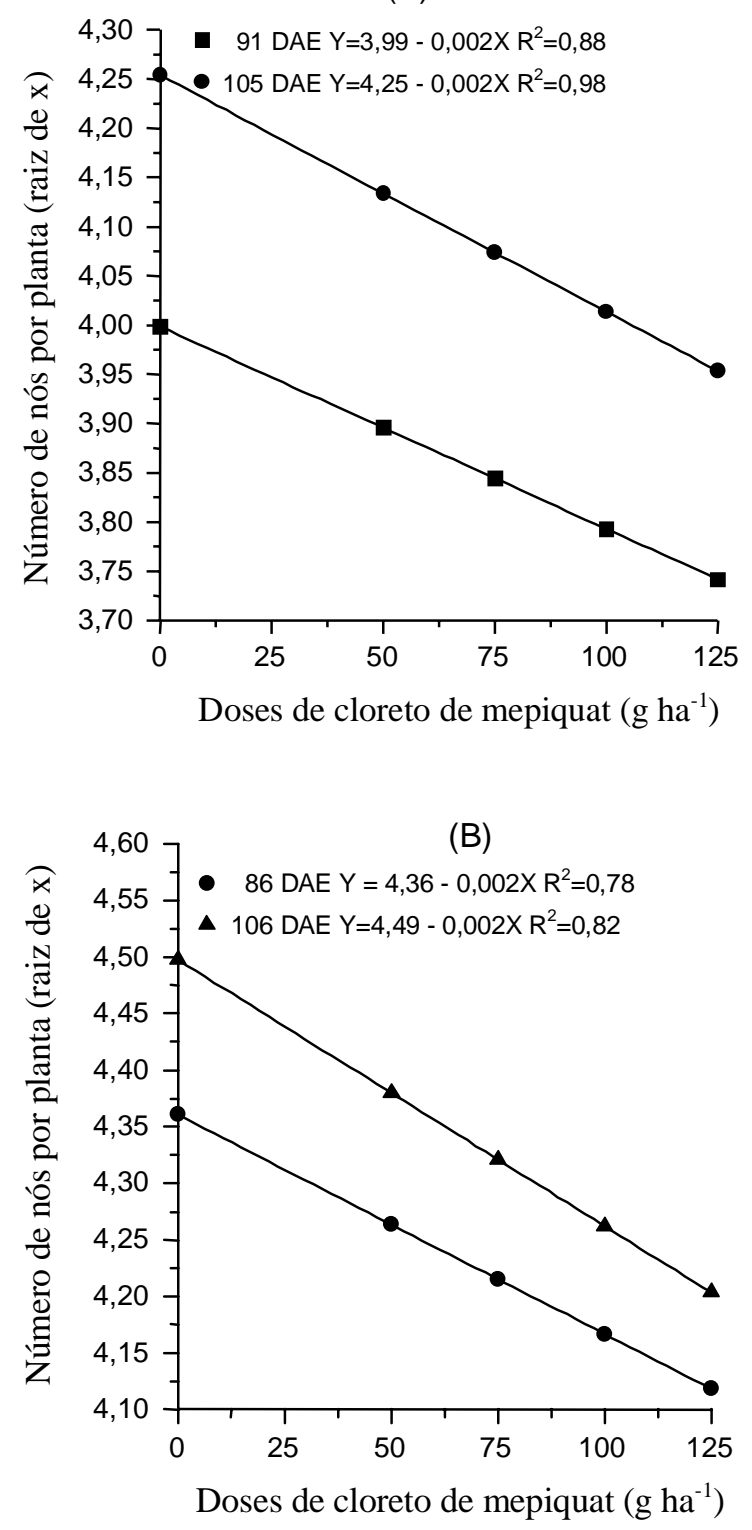

FIG. 7. Efeito das doses de cloreto de mepiquat no número de nós da haste principal, aos 91 e 105 DAE, em 1993/94 (A) e aos 86 e 106 DAE, em 1994/95 (B). Ponta Porã, MS, 1994/95.

Pesq. agropec. bras., Brasília, v.35, n.3, p.507-516, mar. 2000 
Aos 129 DAE, no ano agrícola de 1993/94, quando aproximadamente $70 \%$ dos capulhos estavam totalmente abertos, o número de maçãs por planta decresceu linearmente com o aumento da dose de cloreto de mepiquat (Fig. 9), significando que, quando da avaliação, nos tratamentos que receberam o cloreto de mepiquat, a maioria dos frutos já tinha se transformado em capulhos. De acordo com Wallace et al. (1993), o cloreto de mepiquat proporciona maior retenção de frutos nas primeiras posições, contribuindo para maior precocidade, o que é de grande importância no caso de colheita mecânica, para o controle de pragas de ocorrência tardia como a lagarta-rosada Pectinophora gossypiella (Saunders, 1844) e o bicudo-do-algodoeiro, Anthonomus grandis (Boheman, 1843).

O número de capulhos por planta, ao contrário do número de maçãs, aumentou linearmente com o aumento da dose de cloreto de mepiquat (Fig. 10). Tal resultado foi explicado como sendo devido à maior precocidade proporcionada pelo produto (Hodges et al.,1991).

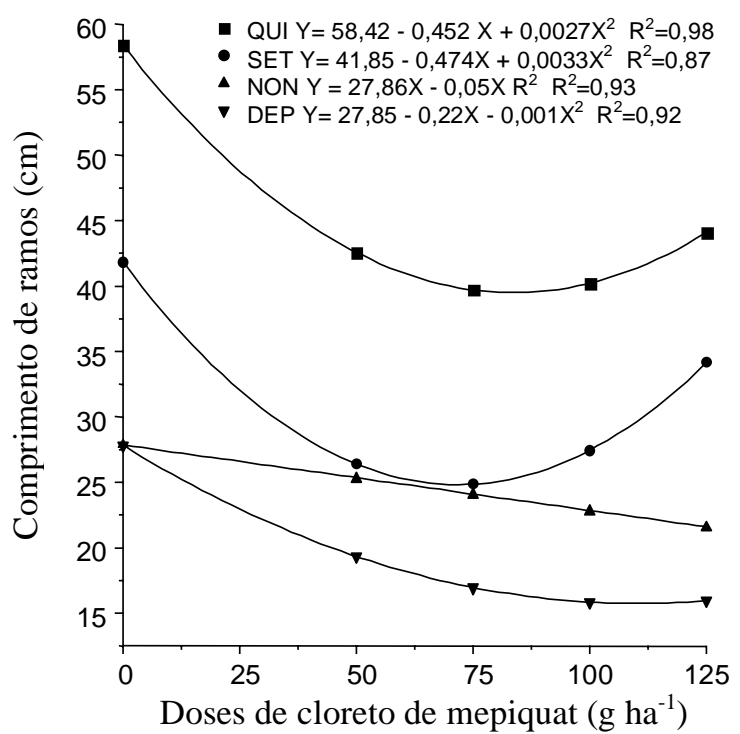

FIG. 8. Efeito das doses de cloreto de mepiquat no comprimento de ramos do quinto (QUI), do sétimo (SET), do nono (NON) e do décimo primeiro (DEP) nó da haste principal, aos 105 DAE, em 1993/94. Ponta Porã, MS, 1993/94.

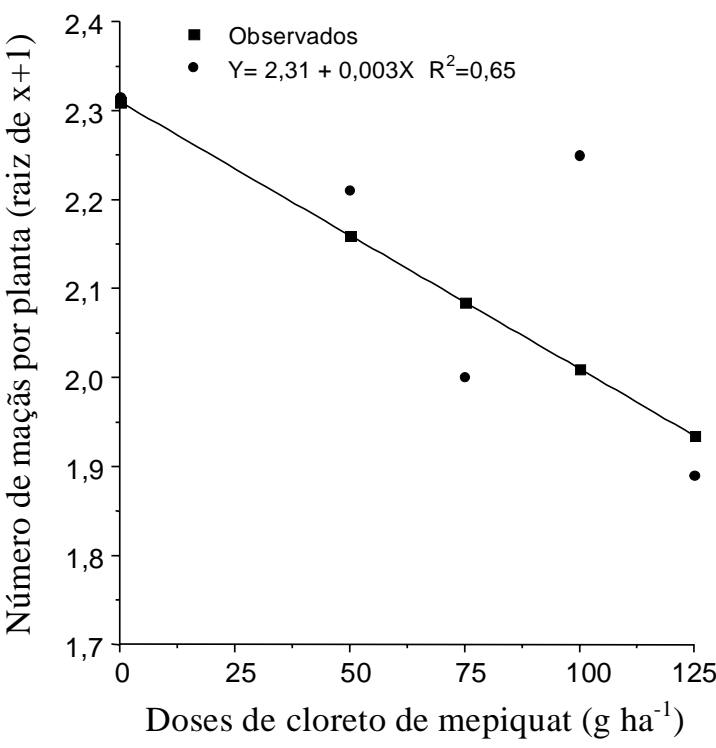

FIG.9. Efeito das doses de cloreto de mepiquat ( $\left.\mathrm{g} \mathrm{ha}^{-1}\right)$ sobre o número de maçãs por planta, aos 129 DAE. Ponta Porã, MS, 1993/94.

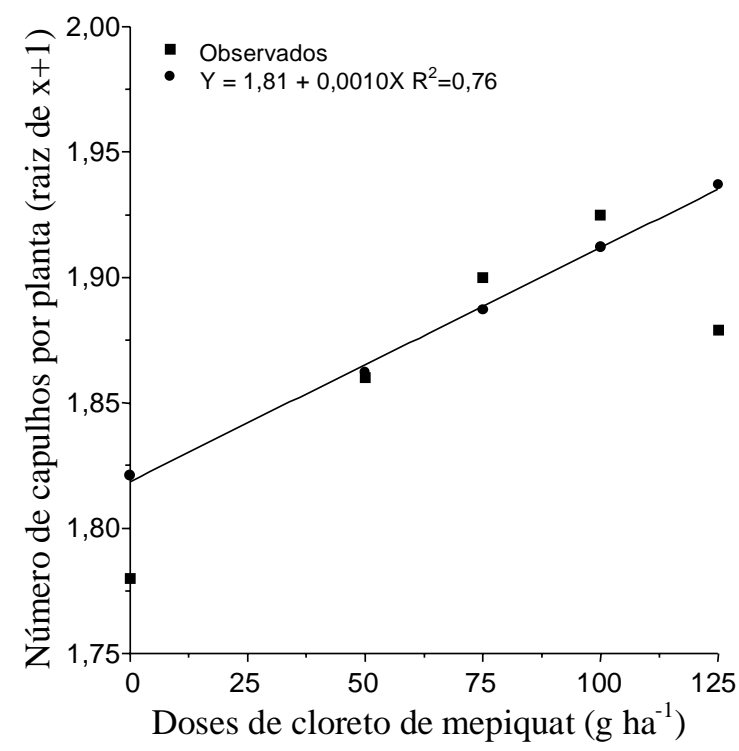

FIG. 10. Efeito das doses de cloreto de mepiquat sobre o número de capulhos por planta, aos 129 DAE. Ponta Porã, MS, 1993/94. 
Nos dois anos em que os estudos foram conduzidos, com o aumento da dose de cloreto de mepiquat, verificou-se redução do número de frutos danificados (Fig. 11), nas avaliações realizadas aos 129 e

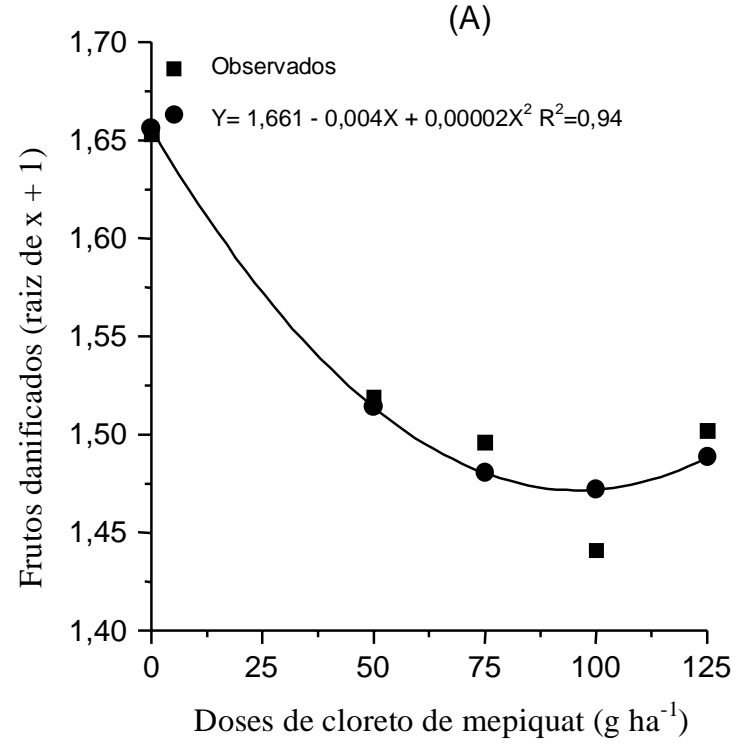

(B)

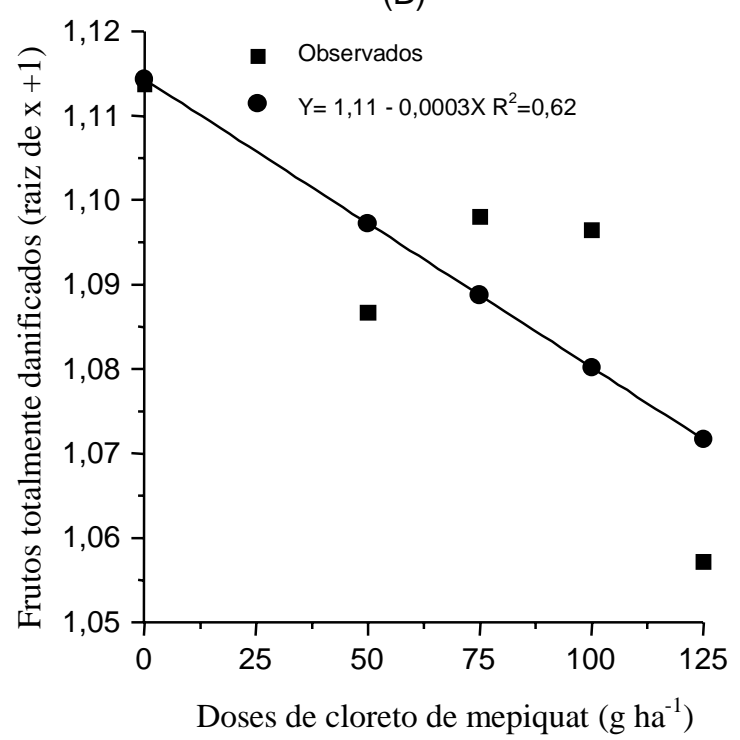

FIG. 11. Efeito das doses de cloreto de mepiquat no número de frutos danificados por planta em 1993/94 (A) e o número de frutos totalmente danificados por planta, em 1994/95 (B), aos 134 DAE. Ponta Porã, MS, 1994/95.
134 DAE, em 1993/94 e 1994/95, respectivamente. A melhor arquitetura da planta em função da aplicação do cloreto de mepiquat, proporciona uma melhor distribuição da calda de inseticidas ao longo do dossel das plantas, além de permitir uma melhor penetração da radiação solar, criando assim um microclima menos favorável ao desenvolvimento de agentes causais de apodrecimento de frutos. Esses resultados são semelhantes aos encontrados por Cruz et al. (1982) e Cothren \& Oosterhuis (1993).

O cloreto de mepiquat uniformiza a produção de botões florais, ocasionando o escape das pragas tardias. Plantas tratadas com cloreto de mepiquat apresentam menor número de botões florais e maçãs danificadas por larvas de Heliothis (Zummo et al., 1984). A modificação da arquitetura das plantas também pode ter contribuído para melhorar a eficiência na aplicação dos inseticidas, facilitando, assim, a melhor distribuição dos produtos, melhorando o controle de insetos-pragas que atacam os frutos. Trabalhos desenvolvidos por Moreira et al. (1994), no Estado de São Paulo, concluíram que o bicudo é um dos principais responsáveis pelo apodrecimento de maçãs.

\section{CONCLUSÃO}

Com o aumento da dose de cloreto de mepiquat verifica-se redução na altura das plantas, no número de nós da haste principal, no número e comprimento de ramos, na matéria seca foliar, na matéria seca do caule, no número de frutos verdes, no número de capulhos danificados, e aumento do número de capulhos totalmente abertos.

\section{REFERÊNCIAS}

BARBOSA, L.M.; CASTRO, P.R.C. Desenvolvimento e produtividade de algodoeiros sob efeito de reguladores vegetais. Anais da Escola Superior de Agricultura Luiz de Queiroz, Piracicaba, v.40, n.1, p.33-86, 1983.

BELTRÃO, N.E. de M. Uso de herbicidas, desfolhantes e hormônios no algodoeiro. In: SEMINÁRIO ESTADUAL COM A CULTURA DO ALGODÃO EM MATO GROSSO, 3., 1996, Cuiabá. Anais. Cuiabá : EMPAER-MT, 1996. p.85-101. (EMPAER-MT. Documentos, 21).

Pesq. agropec. bras., Brasília, v.35, n.3, p.507-516, mar. 2000 
BELTRÃO, N.E. de M.; AZEVEDO, D.M.P. Defasagem entre as produtividades real e potencial do algodoeiro herbáceo: limitações morfológicas, fisiológicas e ambientais. Campina Grande : EmbrapaCNPA, 1993. 108p. (Embrapa-CNPA. Documentos, 39).

CARVALHO, L.H.; CHIAVEGATO, E.J.; CIA, E.; KONDO, J.I.; SABINO, J.C.; PETTINELLI JÚNIOR, A.; BORTOLETTO, N.; GALLO, P.B. Fitorreguladores de crescimento e capação na cultura algodoeira. Bragantia, Campinas, v.53, n.2, p.247254, 1994.

CARVALHO, L.H.; FURLANI JÚNIOR, E. Sistema de produção do algodão mecanizado. In: SEMINÁRIO ESTADUAL COM A CULTURA DO ALGODÃO EM MATO GROSSO, 3., 1996, Cuiabá. Anais. Cuiabá : EMPAER-MT, 1996. p.105-113. (EMPAER-MT. Documentos, 21).

CIA, E.; CARVALHO, L.H.; KONDO, J.I.; FUZATTO, M.G.; BORTOLETTO, N.; GALLO, P.B.; CRUZ, L.S.P.; SABINO, N.P.; PETTINELLI JÚNIOR, A.; MARTINS, A.L.M.; SILVEIRA, J.C.O. Efeito do cloreto de clorocolina e cloreto de mepiquat na cultura do algodão (Gossypium hirsutun L.). Planta Daninha, Campinas, v.7, n.2, p.23-36, 1984.

COTHREN, J.T.; OOSTERHUIS, D.M. Physiological impact of plant growth regulators en cotton. In: BELTWIDE COTTON PRODUCTION RESEARCH CONFERENCES, 1993, Dallas. Proceedings. Memphis : National Cotton Council, 1993. p.128-132.

CRUZ, L.S.P.; SABINO, N.P.L.; TOLEDO, N.M.P. Efeitos do cloreto de mepiquat empregado como fitorregulador sobre algodoeiro herbáceo (Gopssypium hirsutun L. IAC 16). Planta Daninha, Campinas, v.5, n.1, p.15-22, jun. 1982.

FERNANDEZ, C.J.; COTHREN, J.T.; McINNES, K.J. Partitioning of biomass in well-watered and waterstressed cotton plants treated whit mepiquat chloride. Crop Science, Madison, v.31, n.5, p.1224-1228, Sept./Oct. 1991.

HEITHOLT, J.J.; MEREDITH JUNIOR, W.R.; WILLIFORD, R. Comparison of cotton genotypes varying in canopy characteristics in $76-\mathrm{cm}$ vs. 102-cm rows. Crop Science, Madison, v.36, n.4, p.955-960, July/Aug. 1996.
HODGES, H.F.; REDDY, V.R.; REDDY, K.R. Mepiquat chloride and temperature effects on photosynthesis and respiration of fruiting cotton. Crop Science, Madison, v.31, n.5, p.1302-1308, Sept./Oct. 1991.

LACA-BUENDIA, J.P. Efeito de doses de regulador de crescimento no algodoeiro (Gossypium hirsutun L.). Revista Brasileira de Fisiologia Vegetal, Londrina, v.1, n.1, p.109-113, 1989.

MAUNEY, J.R. Vegetative growth and development of fruiting rites. In: MAUNEY, J.R.; STEWART, J.M. (Eds.). Cotton physiology. Memphis : The Cotton Foundation, 1986. p.11-28.

MEREDITH JUNIOR, W.R.; WELLS, R. Potential for increasing cotton yield through enhanced partitioning to reproductive structures. Crop Science, Madison, v.29, n.3, p.636-639, May/June 1989.

MOREIRA, P.H.R.; SOARES, J.J.; BUSOLI, A.C.; CRUZ, V.R. da; PIMENTEL, M.H.L.; PELINSON, G.J.B. Causas do apodrecimento de maçãs do algodoeiro. Pesquisa Agropecuária Brasileira, Brasília, v.29, n.10, p.1503-1507, out. 1994.

REDDY, V.R.; BAKER, D.N.; HODGES, H.F Temperature and mepiquat chloride effects on cotton canopy architecture. Agronomy Journal, Madison, v.82, n.2, p.190-195, Mar./Apr. 1990.

REDDY, V.R.; TRENT, A.; ACOCK, B. Mepiquat chloride and irrigation versus cotton growth and development Agronomy Journal, Madison, v.84, n.6, p.930-933, Nov./Dec. 1992.

STUART, B.L.; ISBELL, V.R.; WENDT, C.W.; ABERNATHY, J.R. Modification of cotton water relations and growth with mepiquat chloride. Agronomy Journal, Madison, v.76, n.4, p.651-655, July/Aug. 1984.

WALLACE, T.P.; SNIPES, C.E.; WHITE, B.W. Effects of single and multiple applications of mepiquat chloride on Mississippi cotton. Starkville : MSU, 1993. 5p. (MAFES. Research Report, v.18, n.5).

YORK, A.C. Cotton cultivar response to mepiquat chloride. Agronomy Journal, Madison, v.75, n.4, p.663-667, July/Aug. 1983.

ZUMMO, G.R.; BENEDICT, J.H.; SEGERS, J.C. Effect of the plant growth regulator mepiquat chloride on host plant resistance in cotton to bollworn (Lepidoptera: Noctuidae). Journal of Economic Entomology, Lanham, v.77, n.4, p.922-924, Aug. 1984. 